\title{
The Effect of Soot Particulate towards MAPK Expression in the Mechanism of Cardiovascular System Disruption
}

\author{
Dodit Yutanto \\ Department of Cardiology and Vascular Medicine, Faculty of Medicine Universitas Airlangga, \\ Mayjen Prof. Dr. Moestopo Street no 47, Surabaya (60131), Indonesia
}

\begin{abstract}
Background: Air pollution is associated with cardiovascular morbidity and mortality. An oxidative stress arising from particulate matter has been shown to activate a number of redox responsive signaling pathways in target cells. This pathway is involved in gene expression that plays a role in the response to inflammation and pathological changes including the expression of mitogen-activated protein kinase (MAPK).
\end{abstract}

Objective: To describe the effect of soot particulate exposure towards MAPK expression in the mechanism of cardiovascular disruption.

Design: This research was an experimental research by using "post test only control group design" approach.

Subjects: The experiment was conducted in laboratory female rats (Rattus novergicus) and consisted of 3 groups:

Methods: Control group -exposed by soot particulate with the concentration of $532 \mathrm{mg} / \mathrm{m} 3$ an hour each day for 30 days, without soot particulate exposure- $(n=10)$; Treatment 1 group $(n=2)$; Treatment 2 group -exposed by soot particulate with the concentration of $1064 \mathrm{mg} / \mathrm{m} 3$ an hour each day for 30 days- $(\mathrm{n}=12)$.

Results: The soot particulate significantly induced an increase in MAPK expression in the treatment 1 group (the number of immunoreactive cells: 51 (31-216) vs 2 (0-50), $\mathrm{p}=0.001$; immunoreactive score (IRS) index: $2(1-4)$ vs $1(0-2), p=0.048)$ and in treatment 2 group (the number of immunoreactive cells: 73 (17-203) vs 2 $(0-50), p=0.000$; IRS: $2(1-4)$ vs $1(0-2), p=0.01)$ compared to control group. There was a significant increase in MAPK expression which was measured from the total number of immunoreactive cells in Treatment 1 $(\mathrm{p}=0.001)$ and Treatment 2 group $(\mathrm{p}=0.000)$ compared to Control group.

Conclusion: The Exposure to soot particulates significantly increased MAPK expression in experimental rats.

Keywords: soot particulate, mitogen-activated protein kinase (MAPK), oxidative stress, air pollution

\section{Background}

The particulate material in the air comprises a heterogeneous mixture of suspended solid and liquid

\section{Corresponding author:}

Muhammad Aminuddin

Department of Cardiology and Vascular Medicine, Faculty of Medicine Universitas Airlangga, Mayjen Prof. Dr. Moestopo street no 47, Surabaya (60131), Indonesia, phone : +6281999201024

email: muhammadaminuddin2018@outlook.com, particles. These particulate material has various sizes and chemical compositions. The primary particles are released directly into the air like soot from a diesel engine ${ }^{(1)}$. The secondary particles are created through the psychochemical transformation of gases such as the formation of nitrate and sulfate from nitric acid gas and sulfur dioxide (SO2) ${ }^{(2)}$. Sources of particulate materials can be natural and man-made including motor vehicle emissions, tire fragmentation and resuspension of road dust, power plants and other combustion industries, smelting and processing of metals, agriculture, construction and combustion activities, household 
wood burning, pollen, forest fires and agricultural waste, volcanic emissions and etc ${ }^{(3)}$. Although there are thousands of chemicals that have been detected in particulate matter in different locations, there are more commonly found compositions such as nitric, sulfuric, carbon and organic carbon materials, organic compounds, biological compounds and various metals (for instance iron, copper, nickel, zinc, and vanadium) (4).

Soot is a carbon element (C) combustion product of an imperfect hydrocarbon. The perfect combustion will only produce water and carbon dioxide. Carbon is a chemical element which has the following characteristics: has atomic number 6, atomic mass 12.0107 nanomoles, classified as non metal with hexagonal chemical structure. Carbon has 6 electrons, 6 protons with isotope C-11, C-12, C-13, C14, C-15 and formed in combustion with low oxygen level. The sources of the soot producers are from inside and outside the room. The use of firewood as a fuel also produces considerable soot ${ }^{(5)}$.

The soot exposure derived from the remnants of combustion products can affect health through various mechanisms. One of the mechanisms suspected to play a role is the occurrence of oxidative stress resulting in increased reactive oxygen species (ROS) or free radicals in the body. Soot exposure stimulates the release of inflammatory cytokines in addition to macrophages and leukocytes. The stimulation of soot to produce cytokines is associated with the activation of mitogen-activated protein kinase (MAPK) in cells which responds to inflammation ${ }^{(6)}$. The occurrence of activation of MAPK will trigger the release of proinflammatory cytokines which will eventually result in extensive tissue damage in blood vessels. This condition can cause disruption of the cardiovascular system ${ }^{(7)}$.

Based on the elaboration above, the researchers are encouraged to conduct further studies in the effect of exposure to air pollutant particles, especially soot particulate on MAPK expression in the cardiovascular system through an experimental study using experimental rats.

\section{Method}

The experimental unit of this study was female white rats (Rattus novergicus) which fulfilled the research criteria of female rats (Rattus novergicus), aged 4 months (16 weeks), weight 100-200 grams, and healthy. The research was conducted at Biochemical Laboratory of Faculty of Medicine, Universitas Airlangga and Department of Veterinary Anatomy Faculty of Veterinary Medicine, Universitas Airlangga.

This research was an experimental research by using "post test only control group design" approach. It was conducted for 6 months with the stages included: giving particulate exposure for 30 days, laboratory animal surgery after the treatment, MAPK expression examination with immunohistochemical methods ${ }^{(8)}$. The study protocol was approved by the Ethical Commission of Dr. Soetomo General Hospital Surabaya. The primary data which were immunoreactive cell quantities were tested for data distribution using Shapiro-Wilk test or One Way ANOVA parametric statistical test, followed by Post Hoc (Tukey HSD) statistical test. On the other hand, the abnormal data was examined by nonparametric statistical Kruskal-Wallis test and followed by Mann-Whitney U statistical test. The data analysis was processed by using SPSS software version 20 (SPSS, Inc., Chicago, IL) ${ }^{(9)}$.

\section{Results}

Tabel. 1 The total number of immunoreactive cells

\begin{tabular}{|l|l|l|l|}
\hline & $\begin{array}{l}\text { Control } \\
\mathrm{n}=10\end{array}$ & $\begin{array}{l}\text { Treatment 1 (T1) } \\
\mathrm{n}=12\end{array}$ & $\begin{array}{l}\text { Treatment 2 (T2) } \\
\mathrm{n}=12\end{array}$ \\
\hline $\begin{array}{l}\text { The Total Number of } \\
\text { Immunoreactive Cells }\end{array}$ & $8.20 \pm 15.25$ & $77.08 \pm 79.63$ & $83.33 \pm 59.40$ \\
\hline The IRS index & $1.10 \pm 0.738$ & $1.83 \pm 0.835$ & $2.33 \pm 1.073$ \\
\hline
\end{tabular}


Table above shows that there were two data of MAPK expression on rats' heart tissue examined with immunohistochemical technique which were: 1 . The total number of immunoreactive cells in five fields of view in the form of ratio data, 2 . The immunoreactive cell assessed with immunoreactive score (IRS) index in the form of ordinal data. The measurement results of the average number of immunoreactive cells in the Control, Treatment 1 and Treatment 2 groups showed differences among groups [2 (0-50), $51(3-216), 83$ (17-203)]. This immunoreactive score (IRS) index or Remmele scale was the result of multiplication between immunoreactive cell percentage score and color intensity score in immunoreactive cell $\left(\sum=\mathrm{A} \times \mathrm{B}\right)$, with the score of $0-12$.

Table 2. The Evaluation of MAPK Expression Using the Semi-quantitative Scale of according to Remmele and Stegner

\begin{tabular}{|c|c|c|}
\hline & A (Percentage of positive cells) & B (Color reaction intensity) \\
\hline Score 0 & No cells with positive reaction & No color reaction \\
\hline Score 1 & $\leq 10 \%$ cells with positive reaction & low color reaction intensity \\
\hline Score 2 & $11-50 \%$ cells with positive reaction & Medium color reaction intensity \\
\hline Score 3 & $51-80 \%$ cells with positive reaction & Strong color reaction intensity \\
\hline Score 4 & $>80 \%$ cells with positive reaction & \\
\hline
\end{tabular}

Table 2 shows that the brighter color reaction, the higher the score. When cells with positive reaction surpassed more than $80 \%$, the color will be strong to indicate the level of positive reaction.

Table 3 The results of the number of immunoreactive cells and MAPK expression (IRS index) using Mann-Whitney test

\begin{tabular}{|l|l|l|l|}
\hline & Control-Treatment 1 & Control-Treatment 2 & Treatment 1-Treatment 2 \\
\hline $\begin{array}{l}\text { The results of the number of } \\
\text { immunoreactive cells using } \\
\text { Mann-Whitney test }\end{array}$ & 0.001 & 0.000 & 0.507 \\
\hline $\begin{array}{l}\text { The results of MAPK } \\
\text { expression (IRS index) using } \\
\text { Mann-Whitney test }\end{array}$ & 0.048 & 0.010 & 0.217 \\
\hline
\end{tabular}

The data in table 3 above is analyzed using MannWhitney test. There was a significant difference in the number of immunoreactive cells between control group and Treatment $1(\mathrm{p}=0.001)$, and between control group and Treatment $2(\mathrm{p}=0.000)$. However, there was no significant difference between treatment group 1 and Treatment $2(p=0.507)$ (table 3$)$. The data analysis was continued by using Mann-Whitney test. There was a significant difference in the MAPK expression between control group and Treatment $1(\mathrm{p}=0.048)$, and between control group and Treatment $2(\mathrm{p}=0.010)$. However, there was no significant difference between treatment group 1 and Treatment $2(\mathrm{p}=0.217)$. 
Table 4. The results of Kruskal-Wallis test from the number of immunoreactive cells and MAPK expression (IRS index)

\begin{tabular}{|l|l|l|l|}
\hline & Chi-Square & df & Asymp. Sig. \\
\hline $\begin{array}{l}\text { The results of Kruskal-Wallis test from } \\
\text { the number of immunoreactive cells }\end{array}$ & 15.849 & 2 & 0.000 \\
\hline $\begin{array}{l}\text { The results of Kruskal-Wallis test in } \\
\text { MAPK expression (IRS index) }\end{array}$ & 8.003 & 2 & 0.018 \\
\hline
\end{tabular}

Table 4 above shows that the total number of immunoreactive cells in five fields of view was a numerical variable; thus, the normality test was performed. The normality test used was the ShapiroWilk test because the number of samples in all three groups $<50$. The result showed that immunoreactive cell data had abnormal distribution $(\mathrm{p}<0.05)$; therefore, the transformation and normality test were re-performed. The Normality test also showed abnormal distribution ( $p$ $<0.05$ ) so that for analysis of difference of mean number of immunoreactive cell between group used KruskalWallis test. There was a significant difference of the average number of immunoreactive cells among groups with the significance value of $\mathrm{p}=0.000$.

The MAPK expression which was assessed by IRS index was in a form of ordinal data; therefore, the normality test was not performed. The data analysis applied was non parametric statistic Kruskal-Wallis test. There was a significant difference of MAPK expression among groups with significance value $\mathrm{p}=0.018$.

\section{Discussion}

The current evidence suggests that particulate matter (PM) has oxidative properties and induces oxidation-dependent changes in inflammatory cells, such as alveolar macrophages, which are involved in the formation of ROS. The continuous formation of ROS results in oxidative damage towards cellular components and can alter its function. Oxidative stress induced through translocated particulates or released materials has atherogenic effects directly ${ }^{(10)}$.

These effects include the oxidation of lipoproteins, which are involved in the process of atherosclerosis. The oxidative stress in blood vessel walls can disrupt endothelial function through the consumption of nitric oxide (NO) or cofactors. The oxidation and nitration of proteins and DNA are also associated with the progression of atherosclerosis ${ }^{(11)}$. The phagocytosis of air suspended particles activates the transduction pathway that triggers the MAPK cascade and the transcription factors. The exposure to particulate materials will activate Jun N-Terminal Kinase (JNK) and p38 MAPK on different cells. Exposure to bronchial epithelial cells by diesel exhaust particle (DEP) will activate JNK and IL-8 production induced by $\mathrm{p} 38$ MAPK ${ }^{(12)}$.

The activation of p38 MAPK will cause the activation of NF- $\kappa \mathrm{B}$. JNK MAPK is often involved in c-Jun phosphorylation and subsequent activation of the AP-1 transcription factor. Another study reported that the activation of these transcription factors $(\mathrm{NF}-\mathrm{\kappa B}$ and AP-1) occurred after the exposure to airborne particles. $\mathrm{NF}-\kappa \mathrm{B}$ is a major transcription factor that controls apoptotic processes and regulates the transcription of various gene products ${ }^{(13)}$. Thurston on his reserach (2008) shows that inhalation of PM2.5 in rats caused the upregulation of several NF- $\mathrm{KB}$-mediated genes, including TNF- $\alpha$, IL- 6 , and transforming growth factor $\beta$ (TGF- $\beta$ ). Ultrafine carbon black (a compound of the PM10 ultrafine fraction) will induce greater oxidative stress in lung cells than fine carbon and can stimulate transcriptional activation of NF- $\kappa$ B21. Pourazar et al. in his study showed that high-dose DEP exposure (high doses (300 $\mu \mathrm{g} / \mathrm{m} 3$ for 1 hour) can activate both NF$\kappa \mathrm{B}$ and $\mathrm{AP}-1$. In the most recent study, DEP exposure increased EGF-R expression and phosphorylation of tyrosine residues (Tyr 1173), activated JNK, AP-1, p38 MAPK, NF-kB pathways and downstream signals as well as stimulated cytokine production ${ }^{(14)}$.

In this study, there was a significant increase in MAPK expression which was measured from the number of immunoreactive cells in Treatment 1 group $(p=0.001)$ and Treatment 2 group $(p=0,000)$ compared to Control group. This finding is in accordance with 
previous research data that particulate matter has the ability to generate oxidative stress and activate the MAPK cascade. The analysis of MAPK expression between treatment group 1 and treatment 2 showed no significant difference $(p=0,507)$.

The measurement of MAPK expression based on the IRS index also obtained similar results. There was a significant increase in MAPK expression in the Treatment 1 group $(\mathrm{p}=0.048)$ and Treatment 2 $(p=0.01)$ compared to the control group. However, there was no significant difference between treatment group 1 and $2(p=0.217)$. Thus, there was a significant increase in MAPK expression in the Treatment 1 and Treatment 2 groups compared to Control group based on the number of immunoreactive cells as well as the IRS index ${ }^{(7)}$. The results of this study are in accordance with the previous studies. These findings support the hypothesis that exposure to soot particulates can increase MAPK expression in the mechanism of cardiovascular disruption ${ }^{(6)}$.

An interesting result was obtained between the Treatment 1 and Treatment 2 groups that showed an insignificant difference based on the number of immunoreactive cells and the IRS index. This was likely due to an increase in non-linear MAPK expression with an increased dose of soot particulate exposure ${ }^{(15)}$. Another possibility is that it took longer exposure time to elicit a significant difference MAPK expression at the dose of exposure to particulate substance as in this study. Therefore, a further study is required to be conducted with various exposure dosage and exposure time of particulate materials.

\section{Conclusion}

Based on data analysis, there was a significant increase of MAPK expression in rats' heart tissue as the result of exposure to soot particulate. However, this increase in MAPK expression was not linear with an increased dose of exposure to the given particulate material. These findings suggest the possibility of an important role of oxidative stress and pro-inflammatory line activation as a response to soot particulate exposure. The findings in our study are important in explaining how particulate matter, especially soot, can contribute to cardiovascular cases.

Ethical Clearance: The research process involves animals as subject of research that was accordant with the ethical research principle based on the regulation of research ethic committee. The present study was carried out in accordance with the research principles. This study implemented the basic principle ethics of respect, beneficence, nonmaleficence, and justice.

Conflict of Interest: There is no report of conflict of interest involved with this study so far.

Source of Funding: This study is funded by authors' fund only without external funds or donation.

\section{References}

1. Corbin JC, Mensah AA, Pieber SM, Orasche J, Michalke B, Zanatta M, et al. Trace metals in soot and PM2. 5 from heavy-fuel-oil combustion in a marine engine. Environ Sci Technol. 2018;52(11):6714-22.

2. Maharani A, Praveen D, Oceandy D, Tampubolon G, Patel A. Cardiovascular disease risk factor prevalence and estimated 10-year cardiovascular risk scores in Indonesia: The SMARThealth Extend study. PLoS One. 2019;14(4):e0215219.

3. Kalvakala KC, Katta VR, Aggarwal SK. Effects of oxygen-enrichment and fuel unsaturation on soot and NOx emissions in ethylene, propane, and propene flames. Combust Flame. 2018;187:21729.

4. Puspitasari HP, Aslani P, Krass I. Challenges in the care of clients with established cardiovascular disease: lessons learned from Australian community pharmacists. PLoS One. 2014;9(11):e113337.

5. Bennett A, Amin HMF, Cenker E, Roberts WL. Measurements of pressure effects on PAH distribution and 2D soot volume fraction diagnostics in a laminar non-premixed coflow flame. Energy \& Fuels. 2018;32(10):10974-83.

6. Shi X, Wang S, Luan H, Tuerhong D, Lin Y, Liang $\mathrm{J}$, et al. Clinopodium chinense Attenuates Palmitic Acid-Induced Vascular Endothelial Inflammation and Insulin Resistance through TLR4-Mediated NF- $\kappa$ B and MAPK Pathways. Am J Chin Med. 2019;47(01):97-117.

7. Sandra F, Oktaviono YH, Widodo MA, Dirgantara Y, Chouw A, Sargowo D. Endothelial progenitor cells proliferated via MEK-dependent p42 MAPK signaling pathway. Mol Cell Biochem. 2015;400(12):201-6.

8. Mohammadi S, Jalaludin MY, Su TT, Dahlui M, Mohamed MNA, Majid HA. Dietary and physical 
activity patterns related to cardio-metabolic health among Malaysian adolescents: a systematic review. BMC Public Health. 2019;19(1):251.

9. Puspitasari HP, Costa DSJ, Aslani P, Krass I. An explanatory model of community pharmacists' support in the secondary prevention of cardiovascular disease. Res Soc Adm Pharm. 2016;12(1):104-18.

10. Sharma S, Singh VK, Kumar A, Mallubhotla S. Effect of Nanoparticles on Oxidative Damage and Antioxidant Defense System in Plants. Mol Plant Abiotic Stress Biol Biotechnol. 2019;

11. Hassoun Y, James C, Bernstein DI. The Effects of Air Pollution on the Development of Atopic Disease. Clin Rev Allergy Immunol. 2019;1-12.

12. Yamashina A, Tomiyama $H$, Takeda $K$, Tsuda $H$, Arai T, Hirose K, et al. Validity, reproducibility, and clinical significance of noninvasive brachialankle pulse wave velocity measurement. Hypertens Res. 2002;25(3):359-64.

13. Alfano R, Herceg Z, Nawrot TS, Chadeau-Hyam M, Ghantous A, Plusquin M. The Impact of Air Pollution on Our Epigenome: How Far Is the Evidence?(A Systematic Review). Curr Environ Heal reports. 2018;5(4):544-78.

14. Thurston GD, Newman JD. Walking to a pathway for cardiovascular effects of air pollution. Lancet. 2018;391(10118):291-2.

15. Lee $\mathrm{S}$, Lim $\mathrm{S}$, Lee H, Park S. Probing the oxidation reactivity of ultra-low-sulfur diesel soot with controlled particle size and organic mass fraction. J Anal Appl Pyrolysis. 2019;140:264-73. 